\title{
CALCULATION OF MAXIMUM SNOW-AVALANCHE RUN-OUT DISTANCE BY USE OF DIGITAL TERRAIN MODELS
}

\author{
by
}

\author{
K. Lied and R. Toppe
}

(Norwegian Geotechnical Institute, P.O. Box 40, Taasen, 0801 Oslo 8, Norway)

\begin{abstract}
Digital maps and terrain models are used to calculate maximum snow-avalanche run-out distance based on topographic parameters. Maps of 1:50000 scale are found to be accurate enough for the purpose. 113 well-known avalanches are discussed in this paper. A computer system is used to calculate terrain parameters such as rupture area $(A)$, avalanche-path length $(L)$, avalanche-track lengths $\left(L_{1}\right.$, $\left.L_{2}\right)$, and run-out lengths $\left(L_{3}\right)$. Maximum run-out angle $(\alpha)$, avalanche-track angle $(\beta)$, and average angle of rupture zone $(\gamma)$ are also found by computer. The use of computer and terrain model reduces subjective judgement of parameters to a minimum. Run-out distance was found to be best expressed by the regression equation:
\end{abstract}

$\alpha=0.91 \beta+0.08 \gamma-3.5^{\circ} . \quad R^{2}=0.94, \quad S=1.4^{\circ}$.

$L=0.93 L_{1}+0.97 L_{2}+0.61 A+182 \mathrm{~m} . \quad R^{2}=0.96, \quad S=$ $137 \mathrm{~m}$.

\section{INTRODUCTION}

This paper discusses how maximum snow-avalanche run-out distance may be calculated by a combination of topographic parameters and use of a digital terrain model. Digitized maps are being made for extensive areas of Norway. By use of digital terrain models it is possible to identify a set of objective topographic parameters which can be applied in an avalanche run-out model. These topographic parameters are calculated by computer, thereby reducing subjective judgement of parameter values. By means of the computer, numerical values of the parameters are found quickly, and data from a great number of avalanche paths may be handled in a short time.

\section{TOPOGRAPHIC PARAMETERS}

\section{Parameters used in earlier works}

The main ideas and the basic topographic parameters applied in this model were first described by Lied and Bakkehøi (1980), and later by Bakkehøi and others (1983). Terrain parameters shown in Figure 1, worked out on the basis of data from 206 avalanches for which the maximum reach is assumed to be known, were used to calculate the run-out distance. The parameters were defined in the following way:

$\alpha=$ angle of straight line between observed outer end of avalanche debris and starting point.

$\beta=$ angle of straight line between point on terrain profile, where slope angle equals $10^{\circ}$, and starting point.

$H=$ vertical distance from starting point to low point in parabola that best fits the longitudinal profile.

$\theta=$ slope angle of top 100 vertical metres of starting zone.

$y^{\prime \prime}=$ second derivative of the polynomial function $y=a x^{2}+b x+c$ best fitted to terrain profile.
Based on these parameters, the following regression equation was found:

$$
\alpha=0.92 \beta-7.9 \times 10^{-4} H+1.4 \times 10^{-2} H y^{\prime \prime} \theta+0.04 .
$$

Standard deviation $S=2.28^{\circ}$; correlation coefficient $R=$ 0.92 .

Further statistical analysis of the data showed that the variable $\beta$ was the dominating factor of the equation. Using $\beta$ as the only predictor variable, the regression equation obtained was:

$$
\alpha=0.96 \beta-1.4^{\circ} ; \quad S=2.3^{\circ} ; \quad R=0.92 .
$$

Later work (Martinelli, 1986; McClung and Lied, 1987) has confirmed both the principle of using terrain variables as predictors for maximum snow-avalanche run-out distance, and that the $B$-angle is the dominating variable in the prediction of $\alpha$. In the work of Lied and Bakkehoi (1980), other topographic parameters were also tried out in a search for a good $\alpha$-angle correlation. These parameters were maximum width of rupture in the starting zone $(R)$, minimum width of track $(T)$, and maximum width of run-out zone $(D)$.

Altogether 26 combinations of the above seven predictor variables were tried out. The best correlation was found between $\alpha$ and the variables in the first equation. The effect of confinement in the avalanche track was especially studied by applying the parameters $R, T$, and $D$. Basically, it was presumed that an avalanche with a wide rupture zone, which is channelled into a narrow track, has a lower $\alpha$ value (longer reach) than an avalanche following an unconfined path. However, no such tendency was found, and it was concluded that avalanches running in unconfined paths, with a constant width from the starting point to the stopping position, obtain equal $\alpha$ values as confined avalanches when other variables are constant.

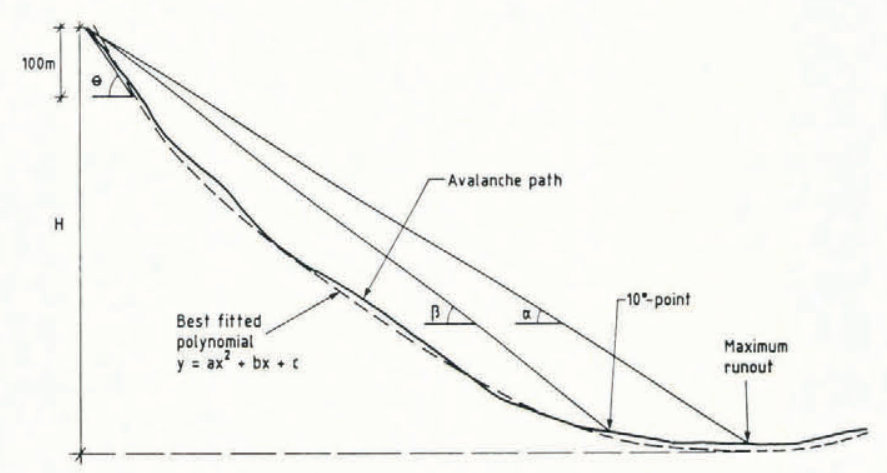

Fig. 1. Topographic parameters from Bakkehøi and others (1983). 


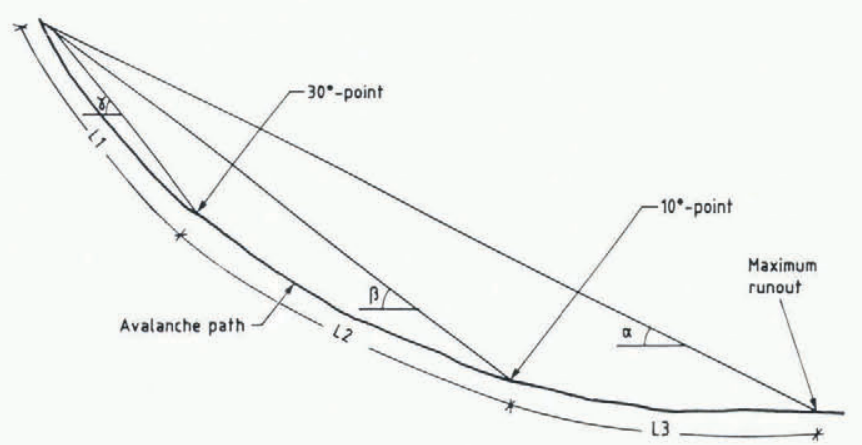

Fig. 2. Topographic parameters in the present paper.

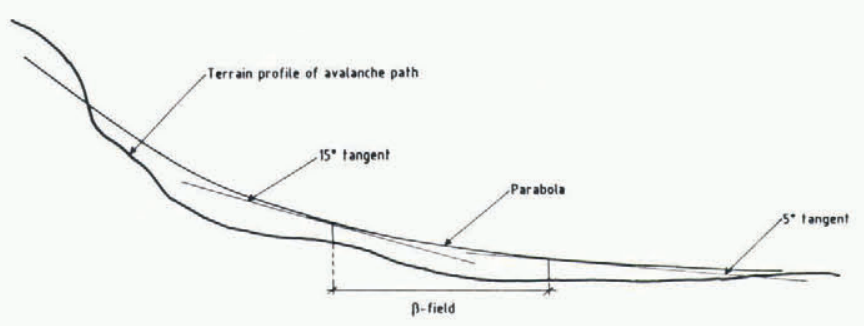

Fig. 3. Definition of $\beta$ field by best-fit parabola.

\section{Topographic parameters used in the present paper}

The $\alpha$ and $\beta$ angles as they are defined in the previous section are used in this paper (Fig. 2).

\section{Area of the starting zone}

One of the factors that may influence run-out distance is the volume of the avalanche. The volume is difficult to calculate in a model where only terrain parameters are included. A correlation between the area of the starting zone and the maximum mass of snow in the avalanche probably exists, as described by Schaerer (1975). Starting zone area $(A)$ is therefore one of the parameters treated in this paper. The same parameter was studied by Bovis and Mears (1976), but their definitions both of the starting zone and the run-out zone are different from the definitions used in this paper and cannot therefore be directly compared. In the present paper, the area of the starting zone is defined as the part of the path lying between the starting point of the avalanche and the $30^{\circ}$ point. The lateral extension of the starting zone is bounded by the local topography from where one single avalanche can be launched, and must be evaluated subjectively.

\section{Average inclination of the starting zone}

Another parameter for describing the characteristics of the starting zone is the angle of the line connecting the lowest point of the starting zone with the starting point ( $\gamma$ angle) (Fig. 2). This parameter describes the average slope inclination of the potential starting zone. In the work of Lied and Bakkehøi (1980), the inclination of the starting zone was introduced as a parameter in run-out calculations $(\theta$ angle). The idea behind the introduction of this parameter was that magnitude of an avalanche partly depends on the terrain inclination in the starting zone. On gentle slopes, avalanches were thought to accumulate more snow before rupture occurs than on steep slopes. If avalanche mass is of importance for the run-out distance, there should be a tendency for low-angle rupture zones to create avalanches with low values of $\alpha$ angles. The analysis showed that the $\theta$ parameter was of minor importance for the prediction of $\alpha$, a result which was confirmed by Bakkehøi and others (1983). By introducing $\gamma$ as a parameter for the inclination of the starting zone, a more logical way of representing the starting zone is achieved, as the terrain slope in the whole of the zone, and not only that in the uppermost $100 \mathrm{~m}$, is included (Mears, 1985).

\section{Length parameters}

Four different length parameters, $L, L_{1}, L_{2}$, and $L_{3}$ are also introduced. These are:

$L=$ total length of avalanche path $\left(L_{1}+L_{2}+L_{3}\right)$ (Fig. 2).

$L_{1}=$ length of the starting zone, defined as distance between starting point and point on the path where slope inclination $=30^{\circ}$.

$L_{2}=$ length of avalanche track, defined as distance between the $30^{\circ}$ point and $10^{\circ}$ point

$L_{3}=$ length of run-out zone, defined as distance from the $10^{\circ}$ point to the outer end of avalanche debris.

\section{DIGITAL MAPS AND THE TERRAIN MODEL}

In Norway the topographic map series on a scale of 1: 50000 , with contour intervals $20 \mathrm{~m}$, has been available in digital form since 1982. The digitized version of the maps has made possible computations based on the map. The terrain-model system, TERMOS, was developed by Stabell and Toppe for the purpose of snow- and rock-slide hazard zoning (Toppe, 1987). The model has a bi-curved surface, built by overlapping cubic spline functions. The spline functions are controlled by a regular grid with a cell size of approximately $30 \mathrm{~m} \times 30 \mathrm{~m}$, when the map scale 1:50000 is concerned, and a total of about one million cells. The elevation and the normal vector are stored for each grid cell.

In this model the terrain surface is mathematically determined. Elevations can quickly be computed anywhere on the surface based on the stored grid. Profiling and computation of real lengths and areas is therefore easily done. The terrain model is accurate and well within the quality demands set by the U.S. Ge-logical Survey. The calculations of the avalanche parameters are performed on a minicomputer (Prime or VAX). Tektronix 4115 or 4125 graphical terminals with puck and tablet are used as work stations. The terminals have built-in zooming and panning functions and all the map handling is performed locally in the work station.

\section{COMPUTATION OF THE AVALANCHE PARAMETERS}

\section{Avalanche path}

As a first step, all avalanches are drawn on a map at the work station; this is done manually using puck and tablet. Each avalanche is drawn to its maximum known extent, after which the centre line of the avalanche is drawn, from the start to the stop position, and the system computes the terrain profile along the path. The bestfitting parabola approximating the profile is computed by a least-squares algorithm.

\section{$\alpha, \beta$, and $\gamma$ parameters}

The $10^{\circ}$ point on the avalanche path is itself identified on the natural profile. To avoid that the model chose small segments with inclination less than $10^{\circ}$ higher up in the path, a $\beta$ point is accepted only if it is inside the section of the profile shown in Figure 3. This section is limited by the points where the angle between the tangent of the best-fit parabola and the horizontal plane is between $5^{\circ}$ and $15^{\circ}$. A similar procedure is performed to identify the $30^{\circ}$ point on the avalanche path. The tangent angle of acceptance for this point is between $25^{\circ}$ and $35^{\circ}$. Note that the purpose of using the parabola is to ensure that the $\beta$ and $\gamma$ points are placed in the correct sections of the real profile. The $\alpha$ angle is then computed, and all three points for $\alpha, \beta$, and $\gamma$ respectively are marked on the profile (Fig. 2). The respective values of the angles are written on the screen.

\section{Area of starting zone}

All areas steeper than $30^{\circ}$ are automatically identified by the computer using the stored normal-vector information. The boundaries of the starting zone have already been described and within these boundaries the computer calculates the real area using a multiple-direction narrow-band algorithm; the lengths of profile lines running across the starting zone are calculated and these lengths are 
multiplied by the distance between the lines to form narrow bands whose width varies with the size of the area. A typical distance is about $50 \mathrm{~m}$. Both the horizontal projection of the area and the real area of the rupture zone are calculated and their values are written on the screen.

\section{RESULTS AND DISCUSSION}

The data set used for the present analysis consisted of topographic parameters derived from 113 avalanche paths in different regions of western Norway. Extreme run-out positions were measured in the field, based on knowledge amongst the local population of the avalanches over a time

$$
\begin{aligned}
& \alpha=0.96 \beta-1.7^{\circ} \\
& \alpha=0.99 \gamma-10.3^{\circ} \\
& \alpha=-0.0092 A+30.3^{\circ} \\
& \alpha=0.0036 L_{1}+24.91^{\circ} \\
& \alpha=0.006 L_{1}-0.008 L_{2}+28.0^{\circ} \\
& \alpha=1.0 \gamma+0.046 L_{1}-13.7^{\circ} \\
& \alpha=0.91 \beta+0.08 \gamma-3.5^{\circ}
\end{aligned}
$$

In Equation (1), both $R$ and $S$ values are high, and these values give better correlations between $\alpha$ and $\beta$ than those obtained in earlier work in which the same parameters have been studied (Fig. 4). The reason for this is probably that the avalanches studied in the present work all exceed the $\beta$ point, which is not the case for all the avalanches examined by earlier workers (Lied and Bakkehøi, 1980; Bakkehøi and others, 1983).

As seen from Equation (2), a correlation between $\alpha$ and $\gamma$ exists $\left(R^{2}=0.56\right)$. The equation has an $S$ value of $3.8^{\circ}$, which is too high for practical applications in run-out distance calculations (Fig. 5).

Except for Equation (1) and (7), the highest $R$ values are found in Equation (6), which is a combination of the average slope of the rupture zone $(\gamma)$ and the length of this zone $\left(L_{1}\right)$. Correlating $(\gamma)$ and $L_{1}$ results in $R^{2}=0.000$, demonstrating that the two variables are statistical independent. The $R^{2}$ value of 0.60 in Equation (6) is a

$$
\begin{aligned}
& L_{3}=0.467 \mathrm{~A}+126 \mathrm{~m} \\
& L_{3}=0.098 L_{1}+148 \mathrm{~m} \\
& L_{3}=0.070\left(L_{1}+L_{2}\right)+118 \mathrm{~m} \\
& L_{3}=0.065 L_{1}+0.074 L_{2}+119 \mathrm{~m} \\
& L_{3}=0.601 \mathrm{~A}-0.04\left(L_{1}+L_{2}\right)+168 \mathrm{~m}
\end{aligned}
$$

The total length of an avalanche path may also be used as a predictor, and regression analysis resulted in these equations:

$$
\begin{aligned}
& L=3.56 A+1080 \mathrm{~m} \\
& L=1.07 L_{1}+1.08 L_{2}+115 \mathrm{~m} \\
& L=0.93 L_{1}+0.97 L_{2}+0.61 A+182 \mathrm{~m}
\end{aligned}
$$

From Equation (13), it can be seen that there is a correlation between the total length of the avalanche path $(L)$ and the size of the rupture area, although the $S$ value is high. A strong correlation also exists with $L, L_{1}$, and $L_{2}$, as is seen from Equation (14). Combined with $A$, the prediction is slightly improved (Equation (14)). The period of at least 100 years. All of the avalanches have terminated on open flat land with no major topographic obstructions in the run-out zone. Most of these avalanches have also been studied by Bakkehøi and others (1983).

For all parameters shown in Table I the range is large, indicating that avalanches differ considerably in length, steepness, and potential rupture area. (A complete list of avalanches and variables is presented in Table II.) Linear regression analyses were performed using $\alpha$ as the dependent variable, and the other listed parameters in Table I as predictor variables. Many different combinations of the predictor variables have been tried and the results clearly demonstrate that $\beta$ is the dominant predictor for $\alpha$. The following equations for $\alpha$ are presented:

$$
\begin{array}{ll}
R^{2}=0.93 & S=1.4^{\circ} \\
R^{2}=0.56 & S=3.8^{\circ} \\
R^{2}=0.05 & S=5.6^{\circ} \\
R^{2}=0.03 & S=5.7^{\circ} \\
R^{2}=0.35 & S=4.7^{\circ} \\
R^{2}=0.60 & S=3.7^{\circ} \\
R^{2}=0.94 & S=1.4^{\circ}
\end{array}
$$

fairly high correlation, but as $S=3.7^{\circ}$ the variation is too high for the handling of run-out problems.

The correlations of $\alpha$ and $A, L_{1}$, and $L_{2}$ all show very low values, as can be seen from Equations (3), (4), and (5). This is not too surprising because $\alpha$, unlike the abovementioned predictors, is a dimensionless number. It is interesting that no relationship seems to exist between the maximum area of a rupture zone and the run-out distance expressed by $\alpha$.

Applying the combination $\alpha=f(\beta, \gamma)$, Equation (7) gives $R^{2}=0.94$ and $S=1.4^{\circ}$. This is a small improvement on the $R$ value in Equation (1). The two predictors are not statistically independent, as $\beta=f(\gamma)$ gives $R^{2}=0.56$ and $S=2.9^{\circ}$.

The possibility of using the path segment $L_{3}$ as a dependent variable has been examined, but no combination of predictor variables seems to give $R$ and $S$ values which would enable sufficiently accurate calculation of run-out distance:

$$
\begin{array}{ll}
R^{2}=0.20 & S=135 \mathrm{~m} \\
R^{2}=0.03 & S=147 \mathrm{~m} \\
R^{2}=0.07 & S=117 \mathrm{~m} \\
R^{2}=0.08 & S=119 \mathrm{~m} \\
R^{2}=0.21 & S=135 \mathrm{~m}
\end{array}
$$

$$
\begin{array}{ll}
R^{2}=0.65 & S=382 \mathrm{~m} \\
R^{2}=0.95 & S=147 \mathrm{~m} \\
R^{2}=0.96 & S=137 \mathrm{~m}
\end{array}
$$

prediction of path lengths according to Equations (14) and (15) will give constant lengths independent of the steepness of the avalanche path. The $\alpha / \beta$ relation (Equation (1)) shows that low values of $\beta$ will create long run-out lengths, which is more realistic and in accordance with what is really found in Nature. 


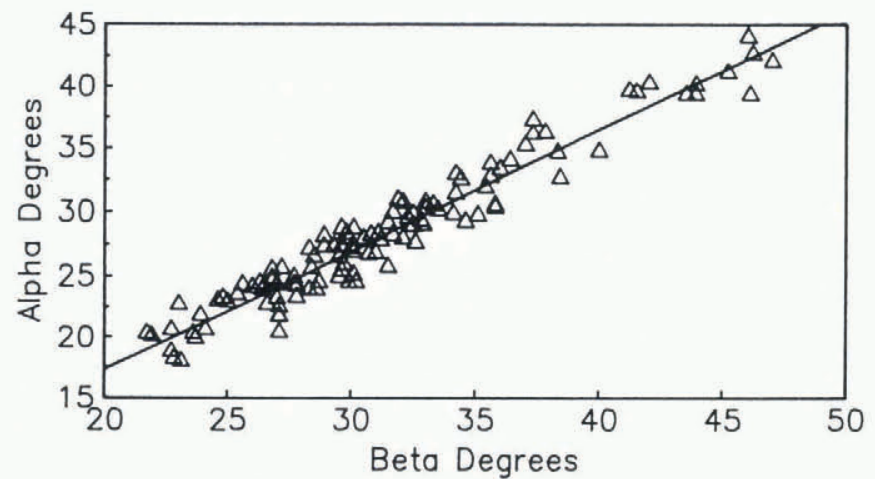

Fig. 4. Observed $\alpha$ angles related to measured $B$ angles, with regression line.

McClung and Lied (1987) used the relation $\delta x / x_{\mathrm{B}}$ as a predictor for the run-out distance; $x_{B}$ was defined as the horizontal distance from the avalanche starting point to the $10^{\circ}$ point, and $\delta x$ as the horizontal distance from the $10^{\circ}$ point to the outer end of the avalanche debris. It was shown that the avalanches with the 50 highest values of this relation gave a very good fit to an extreme-value distribution.

The relationship $L_{3} /\left(L_{1}+L_{2}\right)$ for the 113 avalanche paths which are analysed in the present paper are plotted as a histogram (Fig. 6). The range of observations is from 0.027 to 0.503 , standard deviation $\mathrm{S}=0.092$, median and mean values are 0.130 and 0.148 , respectively.

Forty-five of the avalanches considered have a reach longer than the mean value, and 15 avalanches reach beyond the mean value $+1 S$. When $2 S$ is added to the mean, seven avalanches have a longer reach. Whether the data fit a normal or an extreme value distribution has not been further analysed.

\section{CONCLUSION}

The basic conclusions drawn from this work are that digital terrain models are well suited to the study of avalanche-terrain parameters. Maps at a scale of 1:50000, with contour-line separation of $20 \mathrm{~m}$, seem accurate enough for calculation of maximum snow-avalanche run-out distances. Maps of larger scale would of course add more detail, but would also vastly increase the amount of data and the need for computer resources.

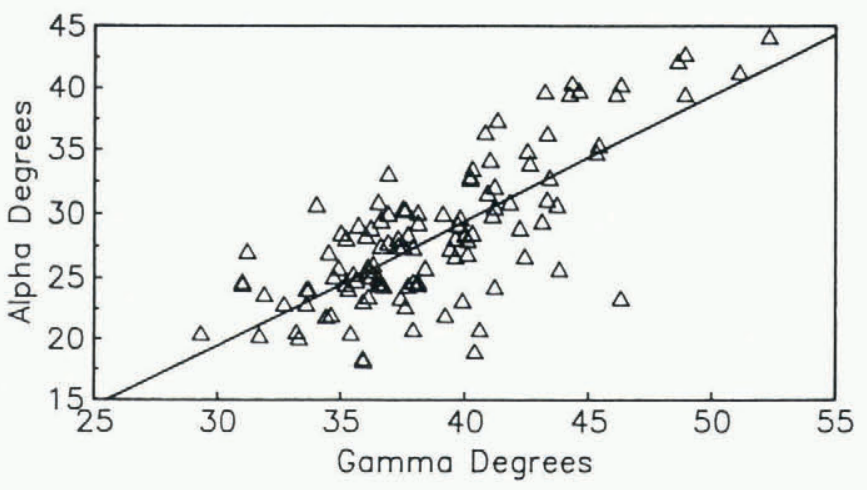

Fig. 5. Observed $\alpha$ angles related to measured $\gamma$ angles, with regression line.

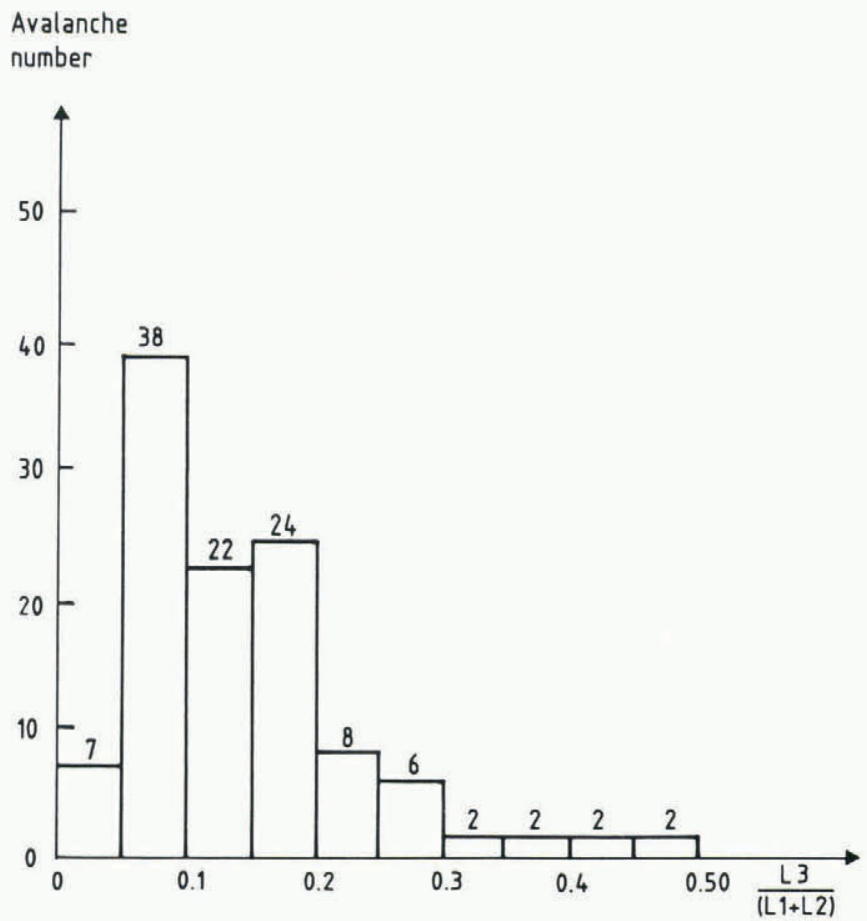

Fig. 6. Histogram of $L_{3} /\left(L_{1}+L_{2}\right)$, and avalanche numbers.

TABLE I. PARAMETERS USED IN ANALYSIS

$\begin{array}{lccccc}\text { Parameter } & \text { Mean } & \text { Median } & \begin{array}{c}\text { Standard } \\ \text { deviation } \\ (S)\end{array} & \text { Min. value } & \text { Max. value } \\ \alpha\left(\left(^{\circ}\right)\right. & 28.2 & 27.3 & 5.8 & 18.0 & 44.0 \\ B\left({ }^{\circ}\right) & 31.3 & 30.1 & 5.8 & 21.7 & 47.0 \\ \gamma\left({ }^{\circ}\right) & 38.8 & 37.9 & 4.4 & 29.3 & 52.3 \\ L_{1}(\mathrm{~m}) & 896 & 914 & 284 & 342 & 1610 \\ L_{2}(\mathrm{~m}) & 773 & 631 & 577 & 103 & 1943 \\ L_{3}(\mathrm{~m}) & 235 & 195 & 151 & 48 & 886 \\ L(\mathrm{~m}) & 1905 & 1802 & 639 & 848 & 3654 \\ A\left(1000 \mathrm{~m}^{2}\right) & 232 & 196 & 145 & 47 & 762\end{array}$


TABLE II. LIST OF AVALANCHES AND VARIABLES

\begin{tabular}{|c|c|c|c|c|c|c|c|c|}
\hline No. & $\alpha$ & B & $\gamma$ & $L_{1}$ & $L_{2}$ & $L_{3}$ & $L$ & $A\left(1000 \mathrm{~m}^{2}\right)$ \\
\hline 1 & 30.1 & 33.5 & 37.6 & 885 & 246 & 178 & 1309 & 109 \\
\hline 2 & 32.5 & 34.4 & 40.2 & 907 & 304 & 48 & 1259 & 79 \\
\hline 3 & 32.7 & 35.6 & 40.2 & 874 & 335 & 97 & 1306 & 80 \\
\hline 4 & 34.6 & 38.3 & 45.3 & 519 & 220 & 138 & 877 & 61 \\
\hline 5 & 20.3 & 23.6 & 29.3 & 596 & 1250 & 370 & 2216 & 174 \\
\hline 6 & 30.5 & 35.8 & 43.7 & 704 & 414 & 229 & 1347 & 96 \\
\hline 7 & 32.6 & 38.4 & 43.4 & 757 & 175 & 247 & 1179 & 80 \\
\hline 8 & 30.3 & 35.8 & 41.2 & 690 & 368 & 231 & 1289 & 47 \\
\hline 9 & 25.7 & 31.5 & 36.1 & 1194 & 447 & 370 & 2011 & 177 \\
\hline 10 & 25.6 & 27.2 & 34.9 & 596 & 580 & 71 & 1247 & 85 \\
\hline 11 & 27.8 & 31.2 & 40.1 & 656 & 548 & 96 & 1300 & 130 \\
\hline 12 & 27.9 & 30.5 & 35.2 & 550 & 654 & 156 & 1360 & 120 \\
\hline 13 & 24.5 & 30.2 & 37.9 & 384 & 345 & 196 & 925 & 60 \\
\hline 14 & 22.5 & 27.1 & 37.6 & 527 & 570 & 260 & 1357 & 130 \\
\hline 15 & 29.7 & 35.1 & 41.1 & 820 & 472 & 251 & 1543 & 87 \\
\hline 16 & 25.9 & 29.7 & 36.3 & 825 & 575 & 206 & 1606 & 143 \\
\hline 17 & 25.1 & 30.1 & 35.5 & 915 & 445 & 343 & 1703 & 180 \\
\hline 18 & 24.2 & 27.8 & 37.7 & 1144 & 828 & 306 & 2278 & 333 \\
\hline 19 & 25.4 & 29.6 & 36.1 & 996 & 860 & 299 & 2155 & 187 \\
\hline 20 & 21.7 & 27.1 & 34.4 & 999 & 511 & 184 & 1694 & 221 \\
\hline 21 & 20.6 & 22.7 & 37.9 & 914 & 1547 & 309 & 2824 & 257 \\
\hline 22 & 23.9 & 26.4 & 33.6 & 785 & 491 & 384 & 1660 & 156 \\
\hline 23 & 20.4 & 27.1 & 33.2 & 931 & 829 & 886 & 2646 & 377 \\
\hline 24 & 22.7 & 26.6 & 32.7 & 1180 & 899 & 545 & 2624 & 410 \\
\hline 25 & 23.3 & 27.8 & 36.1 & 975 & 432 & 642 & 2049 & 339 \\
\hline 26 & 21.8 & 27.1 & 34.6 & 827 & 558 & 506 & 1891 & 232 \\
\hline 27 & 23.2 & 24.8 & 37.4 & 515 & 928 & 131 & 1574 & 154 \\
\hline 28 & 23.9 & 28.6 & 33.7 & 944 & 1001 & 186 & 2132 & 291 \\
\hline 29 & 24.2 & 26.5 & 36.7 & 1023 & 1599 & 407 & 3029 & 323 \\
\hline 30 & 19.9 & 23.7 & 33.3 & 1604 & 1386 & 664 & 3654 & 584 \\
\hline 31 & 26.5 & 28.5 & 42.4 & 475 & 626 & 209 & 1310 & 76 \\
\hline 32 & 24.5 & 29.9 & 38.1 & 1222 & 1835 & 169 & 3226 & 159 \\
\hline 33 & 28.3 & 29.8 & 40.3 & 842 & 1072 & 152 & 2066 & 116 \\
\hline 34 & 30.7 & 32.1 & 41.8 & 1041 & 921 & 128 & 2090 & 151 \\
\hline 35 & 29.8 & 34.1 & 39.1 & 1024 & 560 & 173 & 1757 & 140 \\
\hline 36 & 31.4 & 34.2 & 40.9 & 1610 & 923 & 354 & 2887 & 490 \\
\hline 37 & 23.9 & 28.3 & 35.3 & 952 & 1187 & 368 & 2507 & 505 \\
\hline 38 & 28.9 & 32.5 & 35.7 & 675 & 281 & 141 & 1097 & 91 \\
\hline 39 & 29.3 & 32.8 & 36.6 & 712 & 424 & 137 & 1273 & 90 \\
\hline 40 & 29.2 & 34.6 & 43.1 & 768 & 609 & 225 & 1602 & 301 \\
\hline 41 & 27.9 & 29.9 & 39.6 & 899 & 1765 & 327 & 2991 & 762 \\
\hline 42 & 25.5 & 26.8 & 43.8 & 785 & 1603 & 163 & 2551 & 333 \\
\hline 43 & 36.1 & 37.3 & 43.3 & 808 & 462 & 143 & 1413 & 106 \\
\hline 44 & 40.1 & 43.9 & 46.3 & 704 & 498 & 113 & 1315 & 92 \\
\hline 45 & 39.3 & 43.9 & 46.1 & 745 & 454 & 118 & 1317 & 90 \\
\hline 46 & 39.5 & 41.5 & 43.2 & 757 & 448 & 109 & 1314 & 123 \\
\hline 47 & 21.8 & 23.9 & 39.2 & 1057 & 1644 & 301 & 3002 & 300 \\
\hline 48 & 27.1 & 28.3 & 39.4 & 465 & 491 & 385 & 1341 & 302 \\
\hline 49 & 23.2 & 27.0 & 46.3 & 878 & 1079 & 357 & 2314 & 345 \\
\hline 50 & 18.2 & 22.8 & 35.9 & 653 & 1213 & 646 & 2512 & 318 \\
\hline 51 & 18.8 & 22.7 & 40.4 & 431 & 655 & 305 & 1391 & 146 \\
\hline 52 & 24.9 & 29.5 & 36.2 & 414 & 246 & 188 & 848 & 54 \\
\hline 53 & 25.6 & 28.4 & 38.4 & 429 & 516 & 62 & 1007 & 72 \\
\hline 54 & 28.7 & 29.6 & 36.2 & 1005 & 756 & 56 & 1817 & 305 \\
\hline 55 & 23.0 & 24.6 & 39.9 & 1316 & 1853 & 300 & 3469 & 485 \\
\hline 56 & 24.3 & 25.6 & 38.1 & 967 & 1267 & 286 & 2520 & 290 \\
\hline 57 & 24.3 & 27.7 & 36.5 & 1354 & 1293 & 459 & 3106 & 387 \\
\hline 58 & 22.9 & 25.0 & 35.9 & 1173 & 1555 & 231 & 2959 & 684 \\
\hline 59 & 18.0 & 23.1 & 35.9 & 836 & 1777 & 193 & 2806 & 327 \\
\hline 60 & 37.2 & 37.3 & 41.3 & 808 & 601 & 64 & 1473 & 122 \\
\hline 61 & 29.9 & 31.7 & 38.1 & 1288 & 920 & 189 & 2397 & 406 \\
\hline 62 & 27.6 & 32.6 & 36.9 & 1190 & 906 & 369 & 2465 & 423 \\
\hline 63 & 24.4 & 26.3 & 36.6 & 958 & 854 & 630 & 2496 & 450 \\
\hline 64 & 23.5 & 25.4 & 31.9 & 1520 & 1736 & 204 & 3460 & 758 \\
\hline 65 & 24.5 & 28.7 & 31.0 & 1125 & 853 & 147 & 2125 & 253 \\
\hline 66 & 39.3 & 43.5 & 44.2 & 1168 & 611 & 205 & 1984 & 257 \\
\hline 67 & 40.2 & 42.0 & 44.3 & 1012 & 971 & 68 & 2051 & 385 \\
\hline 68 & 26.9 & 30.1 & 31.2 & 948 & 1313 & 358 & 2619 & 292 \\
\hline 69 & 30.9 & 31.9 & 43.3 & 1288 & 1943. & 97 & 3328 & 479 \\
\hline 70 & 42.6 & 46.2 & 48.9 & 1222 & 155 & 96 & 1473 & 204 \\
\hline 71 & 41.1 & 45.2 & 51.1 & 1229 & 204 & 92 & 1525 & 164 \\
\hline 72 & 42.0 & 47.0 & 48.6 & 1142 & 103 & 522 & 1767 & 253 \\
\hline 73 & 39.6 & 41.2 & 44.6 & 1155 & 950 & 74 & 2179 & 256 \\
\hline 74 & 39.3 & 46.1 & 48.9 & 958 & 927 & 425 & 2310 & 387 \\
\hline 75 & 24.3 & 27.0 & 31.0 & 1296 & 885 & 477 & 2658 & 372 \\
\hline
\end{tabular}


TABLE II continued

\begin{tabular}{|c|c|c|c|c|c|c|c|c|}
\hline No. & $\alpha$ & $B$ & $\gamma$ & $L_{1}$ & $L_{2}$ & $L_{3}$ & $L$ & $A\left(1000 \mathrm{~m}^{2}\right)$ \\
\hline 76 & 24.6 & 26.8 & 35.6 & 770 & 592 & 156 & 1518 & 242 \\
\hline 77 & 20.6 & 24.1 & 40.6 & 447 & 902 & 210 & 1559 & 167 \\
\hline 78 & 20.1 & 21.9 & 31.7 & 342 & 1371 & 250 & 1963 & 107 \\
\hline 79 & 26.8 & 31.0 & 34.5 & 1066 & 829 & 289 & 2184 & 265 \\
\hline 80 & 27.3 & 29.6 & 37.3 & 963 & 584 & 143 & 1690 & 173 \\
\hline 81 & 24.9 & 27.7 & 34.7 & 1029 & 1095 & 305 & 2429 & 528 \\
\hline 82 & 27.2 & 30.0 & 37.9 & 998 & 1089 & 188 & 2275 & 234 \\
\hline 83 & 26.7 & 30.7 & 40.1 & 914 & 980 & 328 & 2222 & 210 \\
\hline 84 & 27.3 & 29.3 & 37.5 & 839 & 907 & 254 & 2000 & 384 \\
\hline 85 & 22.7 & 23.0 & 33.6 & 761 & 1405 & 58 & 2224 & 271 \\
\hline 86 & 20.3 & 21.7 & 35.4 & 361 & 737 & 182 & 1280 & 106 \\
\hline 87 & 27.9 & 32.1 & 37.3 & 556 & 318 & 189 & 1063 & 73 \\
\hline 88 & 26.5 & 29.5 & 39.6 & 843 & 476 & 224 & 1543 & 98 \\
\hline 89 & 30.7 & 33.0 & 36.5 & 1135 & 318 & 145 & 1598 & 203 \\
\hline 90 & 30.2 & 33.0 & 37.5 & 1000 & 392 & 118 & 1510 & 161 \\
\hline 91 & 27.3 & 28.9 & 36.6 & 653 & 596 & 97 & 1346 & 108 \\
\hline 92 & 30.5 & 33.3 & 34.0 & 544 & 1071 & 314 & 1929 & 194 \\
\hline 93 & 28.3 & 31.1 & 35.0 & 558 & 1090 & 306 & 1954 & 164 \\
\hline 94 & 36.2 & 37.8 & 40.8 & 1297 & 290 & 114 & 1701 & 172 \\
\hline 95 & 33.3 & 36.0 & 40.3 & 1239 & 395 & 136 & 1770 & 278 \\
\hline 96 & 29.8 & 32.5 & 36.9 & 1117 & 499 & 195 & 1811 & 261 \\
\hline 97 & 24.3 & 27.7 & 35.2 & 1211 & 896 & 239 & 2346 & 208 \\
\hline 98 & 29.1 & 31.5 & 38.1 & 1352 & 849 & 195 & 2396 & 247 \\
\hline 99 & 29.5 & 32.3 & 39.8 & 1168 & 756 & 180 & 2104 & 196 \\
\hline 100 & 29.0 & 32.9 & 39.7 & 931 & 760 & 294 & 1985 & 167 \\
\hline 101 & 32.9 & 34.2 & 36.9 & 1472 & 231 & 99 & 1802 & 206 \\
\hline 102 & 31.9 & 35.4 & 41.2 & 1126 & 531 & 162 & 1819 & 196 \\
\hline 103 & 24.8 & 26.8 & 36.5 & 360 & 631 & 145 & 1136 & 90 \\
\hline 104 & 24.1 & 26.0 & 41.2 & 479 & 902 & 106 & 1487 & 152 \\
\hline 105 & 28.7 & 30.1 & 42.2 & 496 & 574 & 72 & 1142 & 158 \\
\hline 106 & 35.2 & 37.0 & 45.4 & 671 & 273 & 67 & 1011 & 123 \\
\hline 107 & 28.2 & 31.7 & 37.7 & 753 & 443 & 218 & 1414 & 165 \\
\hline 108 & 33.7 & 35.6 & 42.6 & 681 & 256 & 122 & 1059 & 123 \\
\hline 109 & 34.0 & 36.4 & 41.0 & 899 & 332 & 99 & 1330 & 197 \\
\hline 110 & 44.0 & 46.0 & 52.3 & 934 & 198 & 56 & 1188 & 142 \\
\hline 111 & 34.7 & 40.0 & 42.5 & 1012 & 171 & 205 & 1388 & 216 \\
\hline 112 & 28.1 & 28.9 & 36.0 & 1023 & 1306 & 124 & 2453 & 240 \\
\hline 113 & 28.2 & 30.8 & 40.0 & 764 & 561 & 174 & 1499 & 200 \\
\hline
\end{tabular}

The analysis presented has confirmed that the prediction of maximum avalanche distance can be based on a two-dimensional terrain profile. Area of rupture zone $(A)$ seems to have no correlation with run-out distance expressed as $\alpha$ angle. When run-out distance is expressed in metres $\left(L_{3}\right)$, the correlation to rupture area is present, but still weak, as $R=0.45$. A similar correlation is found when $L_{3}$ is predicted by rupture area $A$, in combination with length of avalanche track, $L_{1}+L_{2} . S$ values for both these combinations are about $130-150 \mathrm{~m}$.

\section{ACKNOWLEDGEMENTS}

The authors are grateful to members of the avalanche section at NGI who stimulated discussion on the topics presented here.

\section{REFERENCES}

Bakkehøi, S., U. Domaas, and K. Lied. 1983. Calculation of snow avalanche runout distance. Ann. Glaciol., 4, 24-29. Bovis, M.J. and A.I. Mears. 1976. Statistical prediction of snow avalanche runout from terrain variables in Colorado. Arct. Alp. Res., 8(1), 115-120.

Lied, K. and S. Bakkehøi. 1980. Empirical calculations of snow-avalanche run-out distance based on topographic parameters. J. Glaciol., 26(94), 165-177.

McClung, D.M. and K. Lied. 1987. Statistical and geometrical definition of snow avalanche runout. Cold. Reg.Sci. Technol., 13(2), 107-119.

McClung, D.M., A.I. Mears, and P. Schaerer. 1989. Extreme avalanche run-out: data from four mountain ranges. Ann. Glaciol., 13, 180-184.

Martinelli, M., jr. 1986. A test of the avalanche runout equations developed by the Norwegian Geotechnical Institute. Cold Reg. Sci. Technol., 13(1), 19-33.

Schaerer. P. 1975. Relation between the mass of avalanches and characteristics of terrain at Rogers Pass, B.C., Canada. International Association of Hydrological Sciences Publication 104 (General Assembly of Moscow 1971 Snow and Ice), 378-380.

Toppe, R. 1987. Terrain models - a tool for natural hazard mapping. International Association of Hydrological Sciences Publication 162 (Symposium at Davos 1986 - Avalanche Formation, Movement and Effects), 629-638. 